\title{
Correction to: Retrospective Assessment of Behavioral Inhibition in Infants and Toddlers: Development of a Parent Report Questionnaire
}

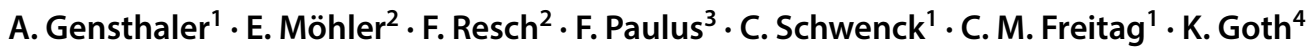

Published online: 14 August 2020

(c) Springer Science+Business Media, LLC, part of Springer Nature 2020

\section{Correction to: \\ Child Psychiatry Hum Dev (2013) 44:152-165 DOI \\ https://doi.org/10.1007/s10578-012-0316-z}

The original version of this article were unfortunately published with an error in "Methods" section. This has been corrected by publishing this correction article.

Under heading "Measures", subsection "Item Construction of the Retrospective Infant Behavioral Inhibition Scale (RIBI)" 5th paragraph, the sentences

"All questions were rated on a 5-point scale $(0=$ Yes, $1=$ more likely Yes, $2=$ partly, $3=$ more likely Not, $4=$ Not). Five of the 20 items remaining after item analysis were worded negatively for inhibition ("She/He involved unfamiliar adults, who came for a visit, directly into her/his play or current activity.") and had to be inversely coded."

should read as

"All questions were rated on a 5-point scale $(0=$ Yes, $1=$ more likely Yes, $2=$ partly, $3=$ more likely Not, $4=$ Not). Five of the 20 items remaining after item analysis were worded negatively for inhibition ("She/He involved unfamiliar adults, who came for a visit, directly into her/his play

The original article can be found online at https://doi.org/10.1007/ s10578-012-0316-z.

A. Gensthaler

Angelika.Gensthaler@kgu.de

1 Department of Child and Adolescent Psychiatry, Psychosomatics and Psychotherapy, Goethe-

University Frankfurt a. M., Deutschordenstraße 50, 60528 Frankfurt a. M., Germany

2 Department of Child and Adolescent Psychiatry, University of Heidelberg, Heidelberg, Germany

3 Department of Child and Adolescent Psychiatry, University Hospital of Saarland, Saarland, Germany

4 Child and Adolescent Psychiatric Hospital, Psychiatric University Hospitals Basel, Basel, Switzerland or current activity.”). The fifteen positively worded items had to be inversely coded prior to data analysis due to the orientation of the Likert scale, to ensure that high behavioral inhibition is indicated by an elevated BI sum score."

According to the methodological procedure initially reported in our article in 2013, high behavioral inhibition in an individual would result in a low RIBI sum score. If data analysis would have been conducted adopting this approach, results of mean BI sum scores would run as follows (also see "Descriptive Statistics, Results" section): "The mean Total BI score in sample 1 was 48.89 ( $\mathrm{SD}=13.20)$. Mean subscores were $19.82(\mathrm{SD}=5.14)$ for Distress to Novelty, 9.03 (SD = 3.12) for Fear and 20.04 (SD = 7.67) for Shyness."

Publisher's Note Springer Nature remains neutral with regard to jurisdictional claims in published maps and institutional affiliations. 